indicating oscillatory movement is more remote, and more easily detached from the sensation. This detachment was difficult for W., in the case of the tuning fork, because it was for him principally an instrument for the inscribing of curves for time-measurement: the sound of the fork signified its motion in space, and the intensity signified the amplitude of the sinusoidal line it could trace. This observation was made by $W$. and reported in practically the words I have used.

The results of observations made by several other subjects give about the same threshold as my own observations. One graduate student, J., perceived no beats at $\mathrm{c}^{\prime}-\mathrm{g} \#$ (56), obtaining perfect fusion at that point, although in auditory experiments the fusion was not complete until 64 was reached. This subject at no time had tendency to confuse the sensation and the motion. $\mathrm{He}$ is quite musical.

Another graduate student, B., reported that he was constantly troubled by the "visualization" of the tuning-fork curve. He perceived clearly the discreteness of the beats up to $c^{\prime}-f \#(78+)$, but beyond that point was unable to decide whether the sensation was or was not continuous.

D., an undergraduate student with previous training in palmesthetic work, and in discrimination of rates and in certain other sorts of psychological observation, obtained clear fusion at $\mathrm{c}^{\prime}-\mathrm{f} \#(781)$ and undoubted discreteness at $c^{\prime}-a(42 \%)$. Between these points, there was doubt, and variation in his judgments.

It should be noted that the differential sensation (above about 80 ) is perceived as exactly like that due to the addition of a third fork, even by subjects who judge it to be a matter of discrete phases. The problem is, therefore, not to decide as to the character of the differential sensation merely, but concerns any vibration of the same rate.

The differential, when faint, may be made perceptible in a way quite similar to that in which the auditory differential is brought out, namely, by stimulating with the lower of the two forks alone for a moment, and then adding the higher; the resultant drop in the pitch of the clang is paralleled by the corresponding change in the felt vibration.

In the tests described herein, the forks were not audible, they being weakly excited, and used at a sufficient distance from the subject's head-at arm's length. In fact, they were scarcely audible when brought up to half the distance from the head.

After making these observations, I am compelled to view with suspicion the results of any simple observations on the threshold of discreteness and fusion in the palmesthetic or haphic realms (and, indeed, in the auditory realm also). I include my own observations in this suspicion, along with others, for while I may say that my observations have been very careful, they can not do more than establish a presumption. Mere observation (" introspection" in the sense of the word now happily becoming obsolete) is productive of no certain results; the measurements I have been describing are excellent vehicles for the demonstration of the fact, and I strongly recommend them to any one who is inclined to rely on the results of simple observation. These observations are not experimental in the proper sense of the word; but fortunately it is possible to apply experimental methods to the problem upon which they bear.

The palmesthetic difference sensation can not be wholly without significance for the theory of auditory perception. Although I have a bias against the "telephone" theory, I must admit that the perception of a difference in vibration rate by dermal or subdermal nerves, and the detection of a differential rate by these same nerves, seems to support strongly the assumption that differences in pitch of sound are not essentially connected with differences in peripheral nervous elements, but that the same cochlear nerve terminations may mediate different pitches, and the same pitch be mediated by different terminations.

Knight DunLaP

\section{ECHINODERM HYBRIDIZATION}

IT is my purpose to call attention in this note to certain facts, the consideration of which may do something toward bringing 
order out of the apparent confusion in which the subject of Echinoderm hybridization is involved.

I may preface my remarks by saying that actually no confusion exists. The apparent confusion is the result of too narrow and restricted a view of the facts, but the student of genetics whose attention has not been called in detail to the matter has no means of realizing that this is true.

In at least two published papers I have made in substance this statement:

It is well known that an apparent confusion exists among observations on hybrid Echinoid larvæ, as to whether plutei of a maternal type, a paternal type or of mixed form are derived from certain crosses. Different results have been obtained by different investigators and by the same investigators working in different regions or in the same region in different seasons.

This statement was made after the consideration of the work of Boveri, Driesch, Morgan, Seeliger, Vernon, Doncaster, Herbst, Steinbrück and others, in connection with my own observations, extending at that time over a period of five years, which were based upon some fifteen successful crosses.

If further proof of the truth of the quoted statement be needed we have it in the results of Hagedoorn, who wrote in 1909 on the "Purely Motherly Character of the Hybrids produced from the Eggs of Strongylocentrotus," and of Loeb, King and Moore, who in 1910, after working on the same type of material, in the same region, reached the conclusion that the hybrids show neither a preponderance of paternal nor of maternal influence.

Again, Shearer, De Morgan and Fuchs in 1911 published a "Preliminary Notice on the Experimental Hybridization of Echinoids," based upon three years' study of three species of Echinus, in which they state the conclusion "that the inheritance of the late larval characters was invariably maternal." In 1912, after another year's work on the same forms they published in the Quarterly Journal of Microscopical Science, Vol. 58,

To our surprise, however, the behaviour of some of the hybrids has differed greatly this season from that of previous years. In late larval life some of the hybrid crosses have shown as strictly a paternal inheritance as in previous years they have shown a maternal one.

It is perfectly evident then that the observations of these later students confirm the truth which I have been trying to establish from my own work, as well as urging that it had already been established by earlier investigators. I emphasize again then the fact that no actual confusion exists. It has been established again and again that under some conditions we may obtain larvæ of a maternal type with respect to certain characters, under other conditions larvæ of a paternal type and under still other conditions larvæ of a blended type. This is established. We should accept the fact.

The real problem in Echinoderm hybridization is the determination of the conditions under which these various types appear.

Another idea to which I wish to call attention is embodied in a statement in the summary of the Shearer, De Margan and Fuchs 1911 paper:

As the result of extensive investigation of the early larval history of our various crosses, we have come to the conclusion that these are too variable to afford any definite evidence of parental influence and especially is this true with regard to the skeleton, heretofore considered the chief index of inheritance.

This generalization from a few crosses should not be applied to all. I am very willing to admit the statement for the Shearer, De Morgan and Fucbs crosses. I can not admit it for some of my own.

In $m y$ investigation of the variation of Echinoid plutei I made a prolonged study of the skeleton of Toxopneustes plutei. I know what the variations in the skeleton under laboratory conditions are, and I determined these variations before drawing $m y$ final conclusions as to the character of the skeleton in hybrids. When the extent and nature of the variations in the skeleton have been determined it may well serve as one of the indices of inheritance in crosses.

Further than this, in proper material, pa- 
ternal influence may be demonstrated in stages even younger than the pluteus. I am now able to show definite and clear-cut evidence of such influence in the early gastrula stage. This evidence will soon be published in detail, so I shall give it here only in summary.

The material from which this proof is gained was obtained in February, 1911, while I was working at the temporary station established by the department of marine biology of the Carnegie Institution in Montego Bay, Jamaica, British West Indies. The research involved the investigation of the normal development of Cidaris tribuloides and of the hybrids obtained by crosses between Cidaris, Hipponö̈ and Toxopneustes.

In its normal development $C$ idaris is unlike the modern Echinoids in that the primary mesenchyme is formed late, the cells arising 23-26 hours after the fertilization of the egg, from the inner end of the archenteron, which has pushed, by this time, well into the blastocole. No mesenchyme cells appear during the blastula stage. In Toxopneustes, as is well known, the primary mesenchyme cells arise about 8 hours after the fertilization of the egg, at the posterior pole of the blastula and have passed into the blastocœle before the beginning of the invagination of the archenteron. A similar condition holds for Hipponoë.

In the Cidaris $+\times$ Toxopneustes $\delta$ and the Cidaris + $\times$ Hippono ${ }^{\circ}$ crosses, gastrulation begins in about 23 hours after fertilization, as in the straight fertilized Cidaris eggs, the process not being noticeably hastened by the use of the foreign sperm. The primary mesenchyme appears about one hour later, the cells arising around the base of the then very short archenteron, at the region of the lips of the blastopore.

The influence of the foreign sperm is thus clearly shown in the changed site of mesenchyme formation. Furthermore, it appears ontogenetically earlier in the hybrids than in the normal Cidaris larvæ.

In calling attention to these matters I do not wish to disparage in any degree the work being done by Shearer, De Morgan and Fuchs and the other British zoologists who have re- cently begun work in this field. Their work on the later stages is admirable. I do wish to plead against the acceptance of negative evidence as the basis for a positive generalization concerning the early stages in Echinoid crosses. Well-chosen material may give positive evidence.

David H. Tennent

\section{SOCIETIES AND ACADEMIES}

THE ACADEMY OF SCIENCE OF ST. LOUIS

AT the regular meeting of the Academy on February 3 and 17, the following papers were read:

Dr. C. H. Turner:" "Apparent Reversal of the Light Responses of the Common Roach.",

Dr. LeRoy McMaster: "The Preparation and Properties of the Ammonium Salts of Some Organic Acids."

Dr. Leo Loeb: "Some Biological Aspects of Tumor Investigation."

Dr. Turner discussed a series of experiments conducted with the common roach (Periplaneta orientalis) for the purpose of seeing if a negatively: phototropic animal could be trained to refuse to enter a specific dark place; and, if that proved possible, for the additional purpose of obtaining an experimental analysis of the behavior.

The electrical punishment method, devised by Professor Yerkes in his study of the dancing mouse, was used.

The speaker stated that he had trained roaches of both sexes and different ages to avoid a specific dark place, and insisted it was equally as logical to interpret his results by concluding that the roach, by means of associated memory, had learned to avoid a specific dark place, as to term its behavior a reversal of negative phototropism.

Professor McMaster described a method of preparing the neutral ammonium salts of monobasic and dibasic organic acids, by dissolving the acids in absolute alcohol or ether and passing dry ammonium gas into the solution. There easily resulted the neutral ammonium salts of succinic, tartaric, ortho- and meta-phthalic, propionic, isobutyric and benzoic acids. Malonic, malic and cinnamic acid salts resulted with difficulty. Analyses showed the compounds to be neutral. ${ }^{2}$

\footnotetext{
${ }^{1}$ Biological Bulletin, Vol. XXIII., 1912, pp. 371386.

${ }^{2}$ This paper will appear in the April number of the American Chemical Journal.
} 